Erik Schleef*

\title{
Individual differences in intra-speaker variation: t-glottalling in England and Scotland
}

https://doi.org/10.1515/lingvan-2020-0033

\begin{abstract}
This paper explores stylistic variation in the use of word-medial and word-final released and glottalled / $\mathrm{t}$ / in London and Edinburgh. Specifically, it investigates the extent to which the social salience of a linguistic feature constrains individual differences in the degree and direction of intra-individual variation. Variation in the social salience of t-glottalling is explored in two linguistic contexts: word-medially, where it is high in London and somewhat lower in Edinburgh, and word-finally, where it is lower than in medial position in both places. Data is based on paired sociolinguistic interviews of 24 London-born adolescents and 21 Edinburgh-born adolescents. Results suggest that while style-shifting norms from speech to reading differ between London and Edinburgh adolescents, they are similar within the communities. However, there are many individual differences in the degree and direction of style-shifting and the latter are more pronounced in final position, where the social salience is weaker. There is also a somewhat large number of Edinburgh adolescents who diverge from the majority norm in medial position and who do not style-shift at all.
\end{abstract}

Keywords: t-glottalling, style, salience, individual differences, intra-speaker variation, adolescents, London English, Edinburgh English

\section{Introduction}

Variationist sociolinguistics has traditionally focused on the patterning of language variation at the level of the speech community. In fact, it has been argued that our sociolinguistic competence, including stylistic variation, is learnt by participation and membership in a particular speech community and that individual language users learn to reproduce the variable patterns of this community (Labov 1972, 2012). For example, Labov (1966) demonstrates this for variable rhoticity of one speaker, who uses the most rhotic tokens when producing minimal pairs, fewer when reading a word list and the least in spontaneous speech - thus replicating the same hierarchy of stylistic constraints as the community as a whole. Guy (1980) too shows that individuals replicate language-internal constraints on word-final consonant cluster simplification in English when sufficient data is available from every speaker.

Although it may be the case that all community members learn the same grammar of a sociolinguistic variable, this does not mean that they produce this variable in the exact same way. First, the usage rate of specific variants may differ from individual to individual while still replicating stylistic and linguistic constraints of the community as a whole. This is not unusual and within predictions of Variationist Sociolinguistics. However, second, it has also been shown that community members may produce a variable in a way that differs from community level constraints (e.g. MacKenzie 2019).

These individual differences may be due to a variety of factors, such as articulatory differences in how speakers produce sounds (e.g. Stevens and Harrington 2014) or differences in their ability to plan speech

*Corresponding author: Erik Schleef, English and American Studies, University of Salzburg, Erzabt-Klotz-Straße 1, 5020 Salzburg, Austria, E-mail: erik.schleef@sbg.ac.at. https://orcid.org/0000-0001-6636-1085

๖ Open Access. @ 2020 Erik Schleef, published by De Gruyter. $(\Theta)$ BY This work is licensed under the Creative Commons Attribution 4.0 International License. 
(MacKenzie 2019) due to individual variation in working memory. Focussing on style-shifting, I argue that in addition to proposals made in previous research, some variables (in some contexts) simply constrain the direction of style-shifting less than others, which results in more individual differences in their use. I will explore this by considering t-glottalling in two linguistic contexts and in two British cities. This article, thus, focuses on the ways in which certain individuals may not reproduce variable stylistic community patterns.

\section{Place, social salience and individual differences}

It is the main goal of this study to explore the roots of the unexpected stylistic behaviour that some individuals appear to show and the conditions that constrain individual differences in intraspeaker variation. I will explore two factors that appear to constrain individual variation: (1) place, and (2) social salience. In this section, I will first discuss (1) and then focus on (2).

Speaker style is dynamic but often highly predictable at the community level: speakers tend to produce more colloquial variants in casual contexts; in contexts which require formality fewer colloquial variants are produced. While individuals usually replicate the community patterns, a few studies have produced evidence that this may not always be the case. In addition to the factors mentioned above, these studies have identified the variable of place to influence the degree of community replication. Johnston 1983 argues that community and individual patterns seem to map onto each other in areas where vernacular and standard are close in structure, but that this is not always the case in peripheral dialect areas for which occasionally so-called "reversals" have been documented, for example more colloquial variants may be used in formal than informal style. Johnston (1983); Milroy (1980); Newbrook (1986) have shown this for Edinburgh, Belfast and West Wirral respectively - especially for working class men. These findings are hard to evaluate as they cannot be compared directly to data collected in different community types, which is why this study focuses on two different cities: London, where vernacular and standard are relatively close in structure, and Edinburgh, where vernacular and standard are further removed.

The second factor I will focus on is that of social salience as it has been suggested that the social salience, in other words the "relative ability [...] to evoke social meaning" (Levon and Fox 2014: 185), of a variant influences stylistic patterns in the community (e.g. Labov's 1972 division of stereotypes, markers and indicators), which would suggest that the social salience must also influence variable behaviour at the individual level. I will test this by investigating the effect of style-shifting on t-glottalling in two linguistic contexts: word-medially and word-finally, as the former has been shown to have a more increased social salience than the latter.

Evidence for these differences in social salience comes from style-shifting behaviour of the community. Schleef (2013: 208-209) has explored this with groups of adolescents in London and Edinburgh. Table 1 summarises these trends. While in final position, the style-shifting behaviour is comparable in London and Edinburgh, which would suggest that in this position t-glottalling is similarly socially salient, t-glottalling in medial position is subject to very pronounced style-shifting behaviour, that is, speakers experience t-glottalling as more socially salient in this position and reduce its use in the more formal style. In addition, the average t-glottalling rates in London are much below those of Edinburgh in speaking style, which would suggest that the social salience of medial t-glottalling in London is more pronounced than that of Edinburgh. Thus, these results would suggest the following difference of social salience ranging from highest to lowest: London medial $>$ Edinburgh medial $>$ London final $>$ Edinburgh final.

Table 1: Percentage t-glottalling in London $(n=2524)$ and Edinburgh $(n=2633)$.

\begin{tabular}{lrrrr}
\hline & \% Medial glottalling & & \% Final glottalling \\
\cline { 2 - 5 } & Speaking & Reading & Speaking & Reading \\
\hline London & $43 \%$ & $7 \%$ & $87 \%$ & $85 \%$ \\
Edinburgh & $91 \%$ & $52 \%$ & $94 \%$ & $89 \%$ \\
\hline
\end{tabular}


Recent dynamic concepts of social salience have questioned the connection between variant and a static social salience and have suggested that not all individuals may share the associations that a variant may carry (e.g. Campbell-Kibler 2008). Different views of the social salience of a variant would, thus, result in different style shifting patterns at the individual level. One would expect more adherences to the community pattern across individuals in the production of the more socially salient context and more inter-individual variation in the less socially salient context. This will be tested in two adolescent communities: one in London, England, and one in Edinburgh, Scotland in order to explore how the social salience of t-glottalling constrains individual differences in degree and direction of style-shifting in these cities and linguistic contexts.

\section{Methods}

\subsection{Data collection}

Data for this study were collected in a high school in West London and one in Edinburgh in 2009. Students were interviewed in friendship pairs of matched origin. The sample consisted of 24 London-born teenagers (12 males, 12 females) and 21 Edinburgh-born teenagers ( 8 males, 13 females). Community-focused results have already been reported in a cross-varietal study in Schleef (2013) and more detail on data collection is available there. The teenagers were all aged between 12 and 18, with a mean age of 14 . Two locally-born female research assistants carried out sociolinguistic interviews, which were transcribed orthographically.

Speakers were also recorded performing a short reading task of 17 sentences that had been designed to elicit a wide range of different phonological variables. The reading task always preceded the interview (for a discussion of order see Meyerhoff et al. 2015: 51). Combining reading and conversational data provides a measure for comparing differences in speech style, in the Labovian sense of attention paid to speech (Labov 1972). The shortcomings associated with using reading and conversational data to elicit different styles are well known, see for example Schilling-Estes (2002: 382-383). Most notably, this method is unidimensional and cannot capture the multitude of different speech styles one may encounter in naturally-occurring speech. Nonetheless, this method can give us some indication of more formal versus less formal speech, and it also allows us to compare the current data to those of other studies.

\subsection{The dependent variable: $/ \mathrm{t} /$}

This study focuses on the variable realisation of $/ t /$, in particular, the alternation between [t], which includes variants, such as $\left.\left.\left[\mathrm{t}^{\mathrm{(h)}},{ }^{\mathrm{P}} \mathrm{t},{ }^{\mathrm{P}} \mathrm{t}\right\urcorner, \mathrm{t}\right\urcorner, \mathrm{t}\right]$, and glottal replacement of $/ \mathrm{t} /$. These two main variants have been coded auditorily. Each realisation of $/ \mathrm{t} /$ occurring in the relevant envelope of variation (i.e. $/ \mathrm{t} / \mathrm{after}$ a preceding sonorant in coda or non-foot-initial onset position) was coded independently by two research assistants. Cases of coding disagreement were discussed with a third researcher and mutually agreed, sometimes after visual inspection of the acoustic properties of particular tokens. The coded data were then imported into Excel for further coding, e.g. for word frequency, grammatical category, style, etc. Not all function words were included in the analysis. Only the first 10 occurrences each of the high frequency function words it, at, but, out, that, not were coded per speaker. This generated 2524 tokens of / $/$ / from the London-born speakers and 2633 tokens of / $t$ / from the Edinburgh-born speakers.

\subsection{Coding for linguistic and social constraints}

T-glottalling is spreading rapidly in Britain and is now perceived as stereotypical of British urban speech in general (Britain 2005: §3; Milroy et al. 1994: 328). The literature on t-glottalling is quite extensive, and it is 
reviewed here very selectively in order to identify factors that previous research has found to constrain variation of $/ \mathrm{t} / .^{1}$

Previous studies typically examine (1) the position of / $/$ / within the word (normally finding that glottal replacement occurs more frequently word-finally than word-medially - cf. Roberts 2006, but see Smith and Holmes-Elliott 2018); and (2) the phonotactic environment (often finding that following segments or prosodic boundaries influence the variability of / $t$ / in statistically consistent ways - see Drummond 2011; Fabricius 2000; Milroy et al. 1994; Straw and Patrick 2007).

The preconsonantal environment usually favours glottal variants the most; the prevocalic environment tends to disfavour it (Straw and Patrick 2007: 390). Findings tend to be constant, but some regional particularities have also been identified (cf. Docherty and Foulkes 1999; Roberts 2006; Smith and Holmes-Elliott 2018). Schleef (2013) found word frequency to be a relevant linguistic factor: more frequent words favour glottal replacement among adolescents in Edinburgh and London. Several social constraints have been investigated in previous research and are often found to be significant for t-glottalling:

- Style: t-glottalling is normally less frequent in formal style (e.g. Holmes 1997, but see Smith and HolmesElliott 2018).

- Age: t-glottalling is more frequent among young speakers (e.g. Fabricius 2000; Roberts 2006; Williams and Kerswill 1999).

- Socioeconomic class and gender: generally, there is more glottalling as one goes down the social scale; however, social class often interacts with gender and the pre-established patterns of use of t-glottalling in an area to generate unique, new patterns (e.g. Holmes 1997; Mees and Collins 1999; Milroy et al. 1994; Roberts 2006).

In the current study, mixed-effect multiple regressions were conducted in $\mathrm{R}$ ( $\mathrm{R}$ Core Team 2019) with style (speaking, reading), social class (working class, mixed, middle class), speaker sex (male, female) and several linguistic factors as fixed and speaker as random effect. This procedure considers individual variation when generating the statistical model and, thus, strengthens our confidence in the model. It allows us to study group patterns while also investigating variation at the individual level.

\section{Results and analysis}

\subsection{Community patterns}

Position, i.e. where in a word / $t$ / occurs, constrains glottal variation of / $t /$ in a highly consistent way. Glottal replacement is much more likely in word-final position. Schleef (2013) created separate models for these two positions in both London and Edinburgh, and he found style to matter in all of them: t-glottalling is significantly more frequent in conversational than in reading style with p-values below $0.001{ }^{2}$ This effect is more pronounced in word-medial position due to the more pronounced stigma attached to word-medial glottal replacement, especially intervocalically (cf. Fabricius 2000: 141). As the exclusive focus in this paper is on style, I will not go into further detail here (see Schleef 2013 for further information). In brief, the following factors favour t-glottalling: preceding vowels and following nasals, liquids, fricatives and affricates. More frequent words are more likely to be glottalled, but the frequency effect is much stronger in word-medial than in final position. In fact, there is no significant frequency effect in word-final position in Edinburgh. Finally, in both cities, there is a strong effect of grammatical category in medial position, for example: function words and verbal progressive forms favour t-glottalling.

1 For a more detailed review of sociolinguistic constraints, see Straw and Patrick (2007) or Schleef (2013). For perceptual questions, see Schleef (2017a), and for developmental aspects, see Schleef (2017b).

2 In London, the model for final position only returns significant results for style when Following Segment is included. 


\subsection{Individual differences: Degree of style-shifting}

What matters for the following argumentation is that at community level, there is clearly a significant style effect. Next, I created separate regression models only including style as a fixed factor in order to conduct a direct comparison between London and Edinburgh on only this one factor. An inspection of the random intercepts suggests that in the medial contexts, the style-shifting behaviour is similar in London and Edinburgh. Figures 1 and 2 show each speaker's random effect, which gives an indication of how much that individual's trend diverges from the predicted trend of the model. The closer the value is to 0 , the less a speaker diverges from the pattern captured by the community model. Speakers with a positive intercept are more likely to glottal; speakers with a negative intercept are less likely to glottal than the model predicts.

Figures 1 and 2 are indicative of a substantial degree of interspeaker variation in both places. While the two figures do not look too dissimilar, the standard deviation and variance are higher in London than they are in Edinburgh (see Table 2). Figures 3 and 4 gives an indication of individual differences in word-final t-glottalling. Table 2 indicates that the degree of interspeaker variation in respect to the model is reduced in final position, when compared to medial position in both London and Edinburgh. Whereas in medial position variance was larger in London than in Edinburgh, in final position the difference between the two places is minimal.

Thus, by means of an intermediate conclusion, I can record that individual differences in the degree of styleshifting differ by place and linguistic context. Individual differences are most pronounced in medial position in London, followed by medial position in Edinburgh, final position in Edinburgh and final position in London.

\subsection{Individual differences: Direction of style-shifting}

While the two statistical models show that speakers style-shift and that there are individual differences in the degree of style-shifting in both cities, it remains unclear whether all speakers shift towards the same direction. Figures 5 and 6 explore this for medial /t/ in London and Edinburgh, and Figures 7 and 8 provide overviews for

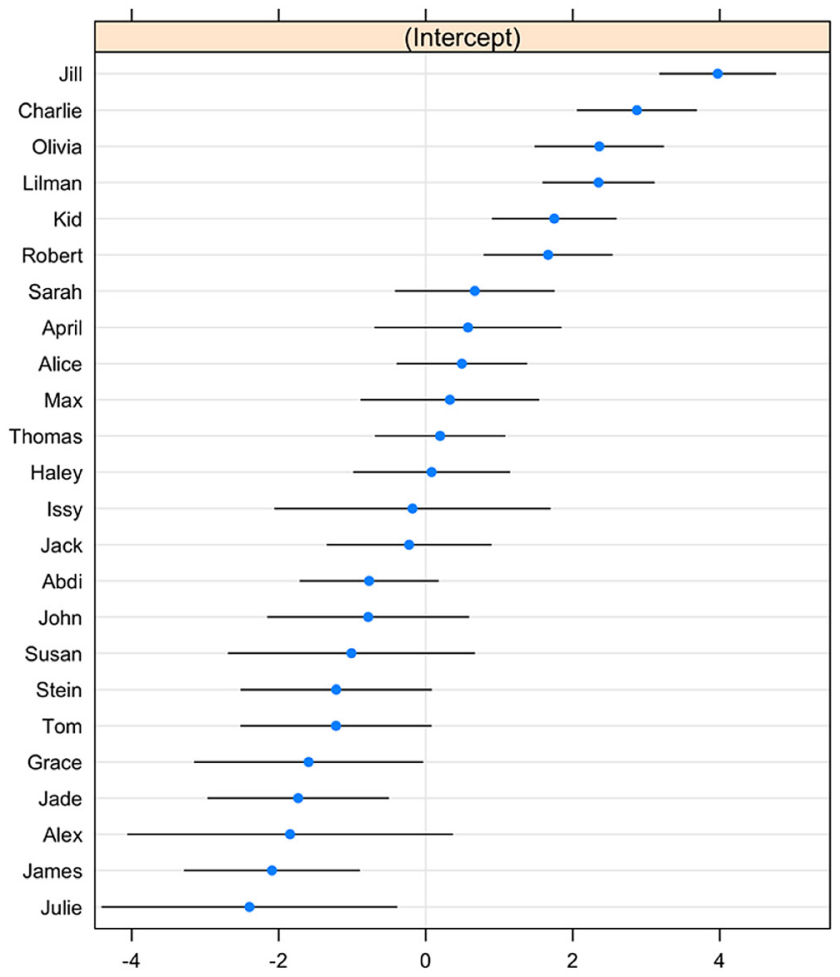

Figure 1: London random intercepts (medial). 


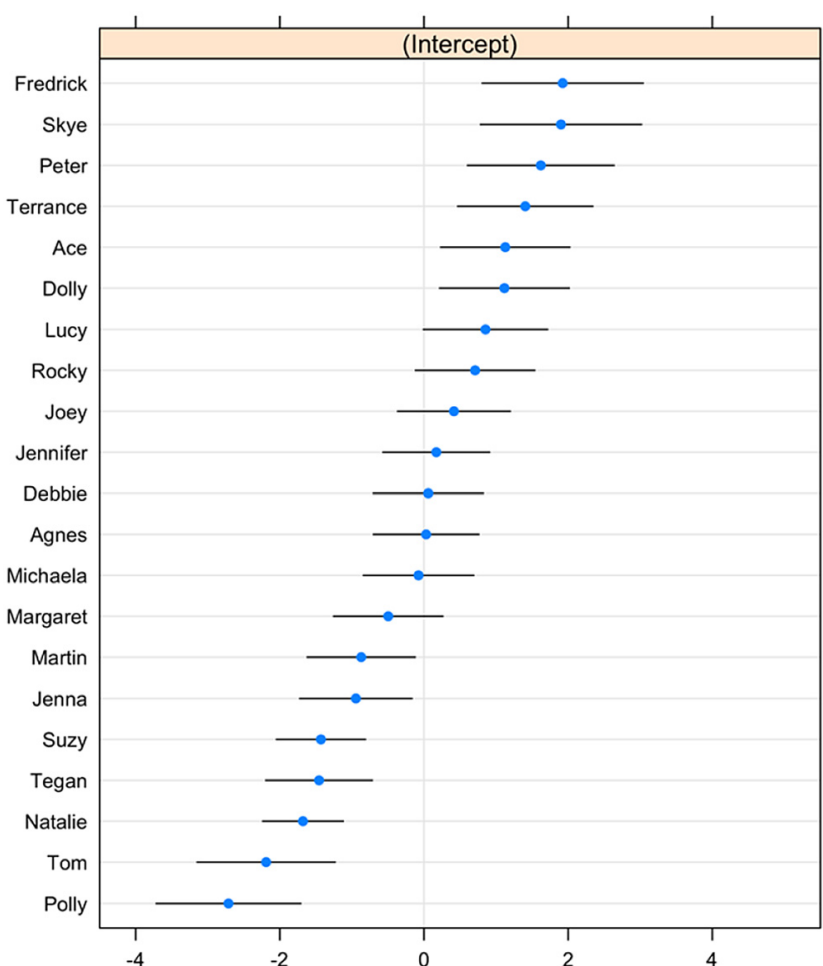

Figure 2: Edinburgh random intercepts (medial).

Table 2: Summary of random effects for Speaker.

\begin{tabular}{lll}
\hline & London & Edinburgh \\
\hline Medial & SD: 1.85 & SD: 1.42 \\
& Variance: 3.42 & Variance: 2.03 \\
Final & SD: 0.51 & SD: 0.57 \\
& Variance: 0.26 & Variance: 0.32 \\
\hline
\end{tabular}

final / $\mathrm{t}$ / (see supporting files for percentage values). A comparison of medial / $t$ / in London and Edinburgh indicates that the community norms in London are very variable in speaking style, while they are more focused to below 30\% glottalling in reading style. In Edinburgh, the situation is reversed. The reading targets differ widely but the conversational target varies less across the community: it is more constrained in Edinburgh at above $80 \%$ glottalling, and, according to Stuart-Smith (2003) obligatory for working class speakers, and optional but frequent for middle class speakers.

We can also observe that in both places the majority of individuals follow the style-shifting behaviour of the community, that is, they reduce glottalling rates in reading style. However, there are a small number of individuals who do not appear to show style-shifting behaviour. In London, Jill, a fourteen-year old working class female with an Indian mother and Jamaican father, does not style-shift at all. Jill has lived in London all her life.

In Edinburgh, five individuals do not reduce their glottalling rates in reading style. Four of these even use slightly higher glottalling rates in read speech. I regard these as cases of a lack of style-shifting rather than as context-induced increases in glottalling as the difference in reading and speaking is never more than $11 \%$. The reading style data is based on a maximum of a 23 medial / $t$ /-tokens, so even one glottalled token can have a large percentage effect. Of those five individuals, all are male, except for Skye, a fourteen-year old female. Four of the five are working class. Terrance, a sixteen-year old male, is middle class. 

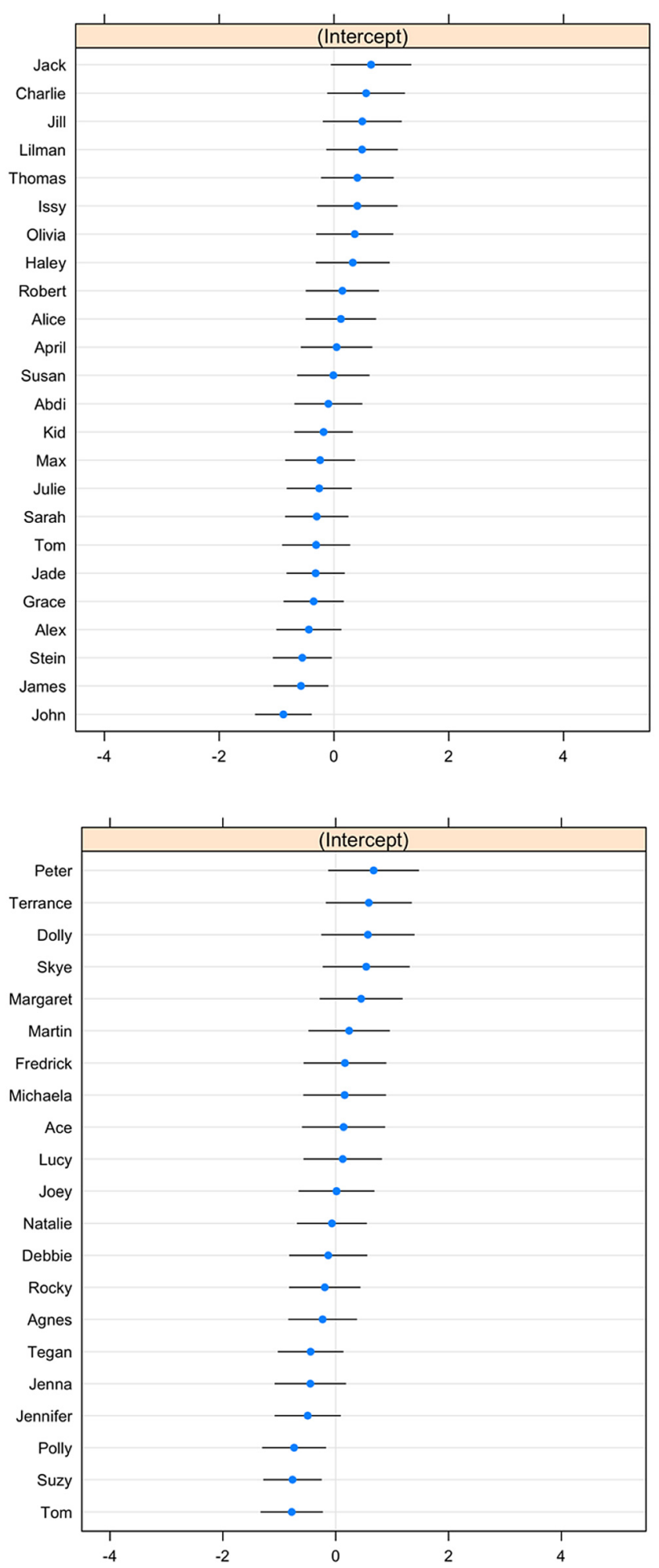

Figure 3: London random intercepts (final).

Figure 4: Edinburgh random intercepts (final).

In regards to the question posed at the beginning of this paper, I can conclude that in medial position, the majority of speakers follow the community pattern, except for one individual in London and five in Edinburgh, which may be a reflection of the higher social salience and stigmatisation of medial t-glottalling in London when compared to Edinburgh. 
Speaking, glottalling in \%

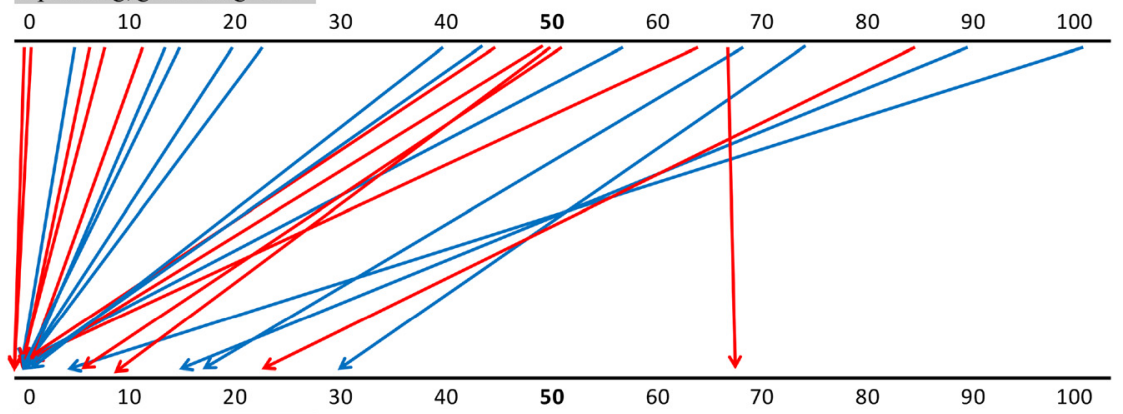

Figure 5: Style among males

Reading, glottalling in \% (blue) and females (red) in medial position - London.

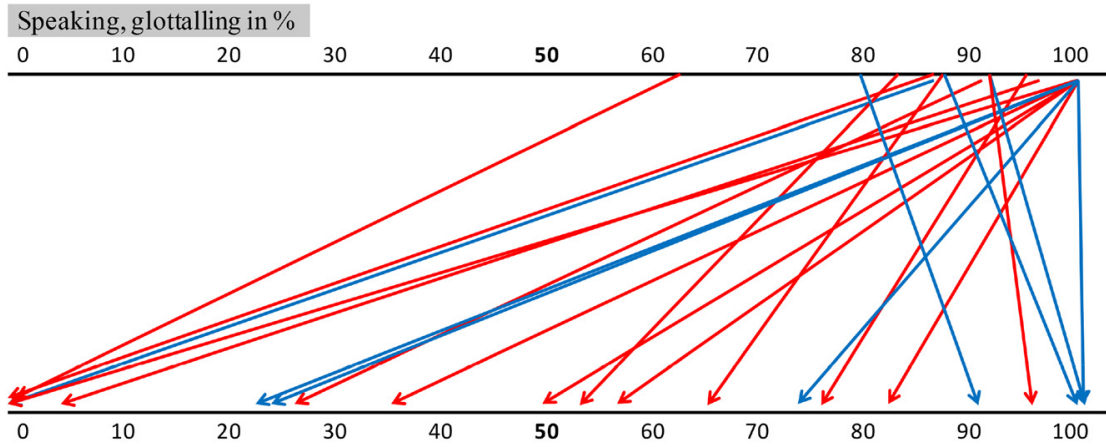

Reading, glottalling in \% (blue) and females (red) in medial position - Edinburgh.

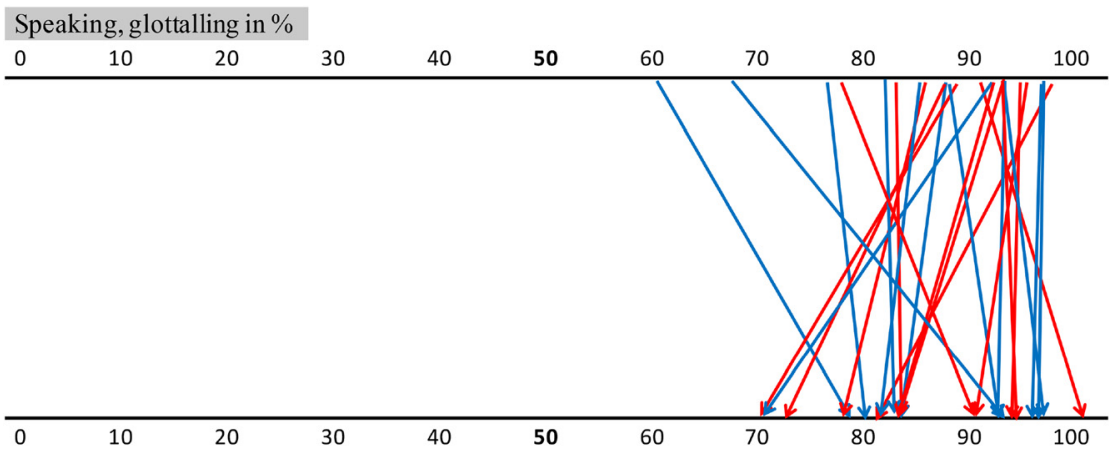

Reading, glottalling in \% final position - London.

Speaking, glottalling in \%

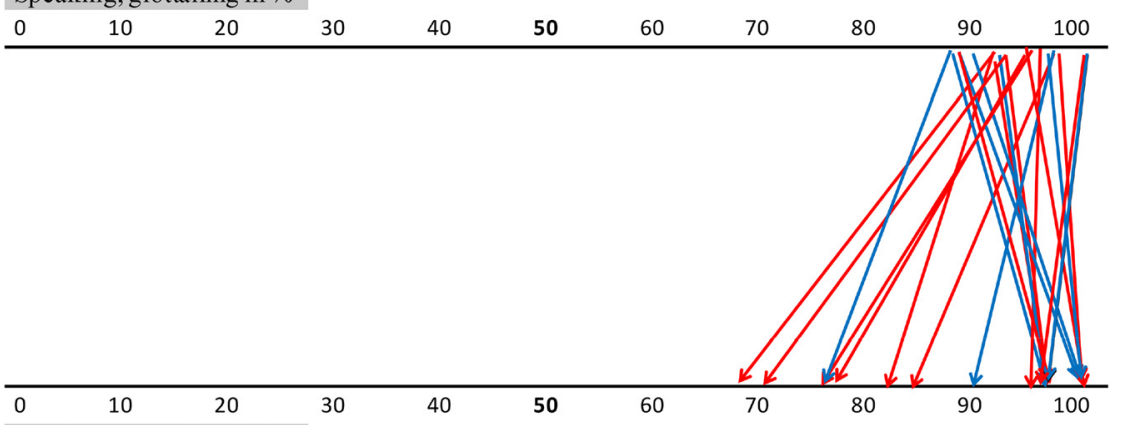

Figure 8: Style among males (blue) and females (red) in Reading, glottalling in \% final position - Edinburgh. 
Table 3: Summary of connection between variance, social salience and individual differences.

\begin{tabular}{llll}
\hline City and context & $\begin{array}{l}\text { Social } \\
\text { salience }\end{array}$ & Individual differences in degree (variance) & Individual differences in shifting direction \\
& Highest & Highest & Low \\
\hline London medial & Mid-high & Mid-high & Mid \\
Edinburgh medial & Low & Lowest & High \\
London \& Edinburgh final & Low & \\
\hline
\end{tabular}

In final position, individual style-shifting behaviour in London and Edinburgh looks more similar than it did for medial position. We still observe slightly more focused conversational glottalling rates in Edinburgh than in London but the reading targets are equally dispersed. Both London and Edinburgh also feature a number of individuals who follow the community model and reduce glottalling rates when reading, however, there is also a remarkably large number of speakers who do not style-shift at all. If we allow for a non-shifting $11 \%{ }^{3}$ range in both directions, only four participants in London and six in Edinburgh shift to less glottalling in reading style. This is in stark contrast to what has been observed in medial position.

In Edinburgh, those who increase glottalling rates in reading style fall within a range of $11 \%$, and I am inclined to regard these as non-shifters. In London, there are three individuals who have much higher glottalling rates in reading style than speaking style: Julie, John and Stein use respectively 12, 19 and 26\% more glottalling in reading than speaking style. However, they stand out from the group not by their glottalling while reading but their high /t/-use when speaking.

This may be due to an important shortcoming of considering reading and speaking as homogeneous styles. While participants may not change their stance and style much while reading, the speaking parts of the interview allow various different personae of participants to surface that the current study cannot control for. Some of those personae constituted by John, Julie and Stein may be ones that are associated with more formal styles of speaking.

When considering the findings as a whole, it appears that the less socially salient context results in less style-shifting and fewer individual differences in degree of shifting, but more individual differences in the direction of style-shifting. The opposite holds true for the more socially salient context. Applied to the two cities and contexts, data from variance and social salience align with individual differences as detailed in Table 3.

\section{Conclusion}

Variance is a relatively good indicator of individual differences in degree of style-shifting. It aligns with social salience because the social salience label was derived from the degree of style-shifting at community level. However, this study has aimed at finding out whether the social salience of a linguistic feature constrains individual differences in the direction of style-shifting. In order to investigate this, I have explored variation in the social salience of t-glottalling in two linguistic contexts: word-medially, where it is high, and word-finally, where it is lower. While this study shows clearly that the style-shifting behaviour differs between $/ \mathrm{t} /$ in medial and final position, results also confirm that not all individuals appear to share the associations that a variant

3 I use $11 \%$ as a value below which I do not consider a person to be style-shifting. This value is specific to this study: there are a maximum of a 23 medial and $33 \mathrm{final} / \mathrm{t} /$-tokens in reading style. To arrive at a value for both contexts, I selected the median of 23 and 33 for further calculations: 28 . Thus, in reading style, one token changes percentage values by $3.5 \%$ on average $(100 / 28=3.5)$, two by $7 \%$ and three tokens by $11 \%$. Considering the low token numbers, percentages of non shifting individuals are unlikely to be the exact same value in both styles. Speakers may be one or two tokens off, possibly even three, but probably not more than that. This is why a value of $11 \%$ was selected. The decision is based in conjecture but it is not completely random. With the low token numbers per individual in mind, it would have been futile to run statistical tests for individual participants to determine such a cut-off value statistically. 
may carry: there are individual differences in the direction of style-shifting and these are more pronounced in final position, where the social salience is weaker. To put it another way, there is more adherences to the community pattern across individuals in the more socially salient context and more inter-individual variation in the direction of style-shifting in the less socially salient context. I will now consider the cases of mid-high and low social salience and relate salience to direction of style-shifting. If there is more room for variability in direction of shifting here, we must ask the question what beliefs give direction to style-shifting behaviour?

In medial position, reading style triggers shifting for some in Edinburgh, for others (many working class males) it does not. There are various explanations for the observed behaviour in medial position. First, a general ambivalence towards norms (also see Johnston 1983) in Edinburgh might explain the results. We would expect speakers to approach Scottish Standard English when reading but there is some ambivalence as to what Scottish Standard English is. Johnston (1983: 11) writes that in Scotland "Standard is defined more in terms of the editing out of dialect features than in conformity to an UMC accent". This might result in a situation in which there is no clear consensus about reading norms at different primary schools or where knowledge about the standard is rather vague. Generally, we have to ask what models are presented in school and to what extent teachers themselves make use of glottalling. This is an important question for future research.

However, the hypotheses regarding reading norms do not represent a good match for the current data because individual differences in shifting direction are driven by speaker sex in Edinburgh. (Not) shifting or (non-)use of t-glottalling in reading may serve as an expression of a particular stance or the constitution of a particular persona that many males and females may feel positive towards. The precise nature of such a stance or persona remains unclear. This could be explored in focus groups or perception tests. It may be the case that some readers feel uncomfortable with the display of middle class values of formality and education associated with released / $t /$. This is in line with Eckert's views about the social meaning of vernacular form. In a discussion of variation of (ing) she writes:

If I am correct in my assumption that class differences involve ideological differences about formality and displays of education, then one might expect working class speakers to have the more positive evaluations of this [the vernacular] form and middle class speakers to have the more negative ones (Eckert 2008: 467).

More positive evaluations of t-glottalling may allow working class speakers to express their preferred stance while reading: one that is associated with less formality and their own class. These class associations may also be entangled with gender. As t-glottalling is more accepted in Edinburgh than in London (in speaking and reading) - this may allow Edinburgh students to use this permitted variability of t-glottalling for gendered work (the link between masculinity and working class associations is well known, e.g. Trudgill 1972) and constitute gendered personae in reading style. These ideas need testing in future research.

Regarding t-glottalling in final position, here too, the lower social salience constrains the direction of styleshifting less, which may result in more individual choices in the use of $/ t /$. Thus, the social salience of a variable is a key to understanding individual differences in degree but especially direction of intraspeaker variation. This study has further shown that unexpected style-shifting patterns are not limited to the so-called periphery, but that they can also occur in areas where the vernacular and the standard are relatively close in structure, as they are in London. This suggests that even here many individuals differ from each other in the social meanings they associate with released and glottalled /t/, especially in final position.

\section{References}

Britain, David. 2005. The dying dialects of England? In Antonio Bertacca (ed.), Historical linguistic studies of spoken English, 35-46. Pisa: Edizioni Plus.

Campbell-Kibler, Kathryn. 2008. I'll be the judge of that: Diversity in social perceptions of (ING). Language in Society 37(5). 637659.

Docherty, Gerard J. \& Paul Foulkes. 1999. Derby and Newcastle: Instrumental phonetics and variationist studies. In Paul Foulkes \& Gerard J. Docherty (eds.), Urban voices: Accent studies in the British Isles, 47-71. London: Arnold.

Drummond, Rob. 2011. Glottal variation in /t/ in non-native English speech: Patterns of acquisition. English World-Wide 32(3). $280-308$. 
Eckert, Penelope. 2008. Variation and the indexical field. Journal of Socioinguistics 12(4). 453-476.

Fabricius, Anne. 2000. T-glottaling between stigma and prestige: A sociolinguistic study of modern RP. Copenhagen Business School PhD dissertation.

Guy, Gregory. 1980. Variation in the group and the individual: The case of final stop deletion. In William Labov (ed.), Locating language in time and space, 1-36. New York: Academic Press.

Holmes, Janet. 1997. Setting new standards: Sound changes and gender in New Zealand English. English World-Wide 18(1). 107-142. Johnston, Paul. 1983. Irregular style variation patterns in Edinburgh speech. Scottish Language 2. 1-19.

Labov, William. 1966. The social stratification of English in New York City. Washington, DC: Center for Applied Linguistics. Labov, William. 1972. Sociolinguistic patterns. Philadelphia: University of Pennsylvania Press.

Labov, William. 2012. What is to be learned: The community as the focus of social cognition. Review of Cognitive Linguistics 10(2). 265-293.

Levon, Erez \& Sue Fox. 2014. Social salience and the sociolinguistic monitor: A case study of (ING) and TH-fronting in Britain. Journal of English Linguistics 42(3). 185-217.

MacKenzie, Laurel. 2019. Perturbing the community grammar: Individual differences and community-level constraints on sociolinguistic variation. Glossa: A Journal of General Linguistics 4(1). 1-23.

Mees, Inger M. \& Beverley Collins. 1999. Cardiff: A real-time study of glottalisation. In Paul Foulkes \& Gerard J. Docherty (eds.), Urban voices: Accent studies in the British Isles, 185-202. London: Arnold.

Meyerhoff, Miriam, Erik Schleef \& Laurel MacKenzie. 2015. Doing sociolinguistics: A practical guide to data collection and analysis. London: Routledge.

Milroy, Lesley. 1980. Language and social networks. Oxford: Blackwell.

Milroy, James, Lesley Milroy, Sue Hartley \& David Walshaw. 1994. Glottal stops and Tyneside glottalization: Competing patterns of variation and change in British English. Language Variation and Change 6(3). 327-357.

Newbrook, Mark. 1986. Sociolinguistic reflexes of dialect interference in West Wirral. Frankfurt am Main: Peter Lang.

R Core Team. 2019. R: A language and environment for statistical computing. Version 3.6.1. Vienna, Austria. Available at: https:// www.R-project.org/.

Roberts, Julie. 2006. As old becomes new: Glottalization in Vermont. American Speech 81(3). 227-249.

Schilling-Estes, Natalie. 2002. Investigating stylistic variation. In Jack K. Chambers, Peter Trudgill \& Natalie Schilling-Estes (eds.), Handbook of language variation and change, 375-401. Oxford: Blackwell.

Schleef, Erik. 2013. Glottal replacement of /t/ in two British capitals: Effects of word frequency and morphological compositionality. Language Variation and Change 25(2). 201-223.

Schleef, Erik. 2017a. Social meanings across listener groups: When do social factors matter? Journal of English Linguistics 45(1). 28-59.

Schleef, Erik. 2017b. Developmental sociolinguistics and the acquisition of T-glottalling by immigrant teenagers in London. In Gunther de Vogelaer \& Matthias Katerbow (eds.), Acquiring sociolinguistic variation, 311-347. Amsterdam: John Benjamins.

Smith, Jennifer \& Sophie Holmes-Elliott. 2018. The unstoppable glottal: Tracking rapid change in an iconic British variable. English Language and Linguistics 22(3). 323-355.

Stevens, Mary \& Jonathan Harrington. 2014. The individual and the actuation of sound change. Loquens 1(1). 1-10.

Straw, Michelle \& Peter L. Patrick. 2007. Dialect acquisition of glottal variation in /t/: Barbadians in Ipswich. Language Sciences 29(2-3). 385-407.

Stuart-Smith, Jane. 2003. The phonology of Modern Urban Scots. In John Corbett, J. Derrick McClure \& Jane Stuart-Smith (eds.), The Edinburgh companion to Scots, 110-137. Edinburgh: Edinburgh University Press.

Trudgill, Peter. 1972. Sex, covert prestige and linguistic change in the urban British English of Norwich. Language in Society 1(2). 179-195.

Williams, Ann \& Paul Kerswill. 1999. Dialect levelling: Change and continuity in Milton Keynes, Reading and Hull. In Paul Foulkes \& Gerard J. Docherty (eds.), Urban voices: Accent studies in the British Isles, 141-162. London: Arnold.

Supplementary material: The online version of this article offers supplementary material (https://doi.org/10.1515/lingvan-20200033). 